\title{
Sevoflurane inhibits the antioxidant capacity of erythrocytes
}

\author{
BO YE ${ }^{1}$, YUN JI $^{1}$, QUAN YUAN ${ }^{2}$, GUO-RONG ZHANG $^{3}$, QIN FAN ${ }^{1}$, GUO WEI $^{1}$, ZHE YIN $^{1}$ and LEI TAO $^{1}$ \\ ${ }^{1}$ Department of Anesthesia, Air Force General Hospital, PLA, Beijing 100142; ${ }^{2}$ Outpatient Department, \\ Shanghai Campus, PLA Nanjing Institute of Politics, Shanghai 200433; ${ }^{3}$ Department of Pain, \\ Air Force General Hospital, PLA, Beijing 100142, P.R. China
}

Received October 21, 2014; Accepted September 29, 2015

DOI: $10.3892 / \mathrm{etm} .2015 .2938$

\begin{abstract}
The aim of the present study was to observe the effects of sevoflurane on the antioxidant capacity, endothelial nitric oxide synthase (eNOS) content and lifespan of erythrocytes. A $2 \%$ erythrocyte suspension was prepared from whole blood collected from healthy volunteers and then treated with sevoflurane at different concentrations (group A, 0\%; group $\mathrm{S} 1,1 \%$; group $\mathrm{S} 3,3 \%$; and group $\mathrm{S} 5,5 \%$ ), in the presence or absence of $200 \mu \mathrm{mol} / 1$ hydrogen peroxide $\left(\mathrm{H}_{2} \mathrm{O}_{2}\right.$, or $\mathrm{H}$ in group names). In order to evaluate the effects of sevoflurane on the antioxidant capacity and NO metabolism of erythrocytes, the hemolysis rate, catalase (CAT) content and eNOS content were determined, while the labeled phosphatidylserine rate and forward scatter of erythrocytes were detected using flow cytometry. Group S3 showed the highest hemolysis rate in the absence $\mathrm{H}_{2} \mathrm{O}_{2}$, while treatment with $\mathrm{H}_{2} \mathrm{O}_{2}$ increased the hemolysis rate of groups $\mathrm{S} 1$ and $\mathrm{S} 3(\mathrm{P}=0.027)$. The CAT content in groups treated with sevoflurane was significantly lower compared with that in the control (group A, air group). The CAT content in groups $\mathrm{S} 1+\mathrm{H}, \mathrm{S} 3+\mathrm{H}$ and $\mathrm{S} 5+\mathrm{H}$ remained significantly lower compared with group $\mathrm{A}+\mathrm{H}(\mathrm{P}<0.05)$. The eNOS content of group A was similar to that of group S3, while the content in group S1 was similar to that in group S5. In addition, the eNOS content of groups A and S3 increased, while that of groups $\mathrm{S} 1$ and $\mathrm{S} 5$ was reduced upon $\mathrm{H}_{2} \mathrm{O}_{2}$ treatment $(\mathrm{P}<0.05)$. The results indicated that sevoflurane reduced the antioxidative activity of erythrocytes, decreasing the resistant ability to $\mathrm{H}_{2} \mathrm{O}_{2}$ damage and increasing the hemolysis rate. The underlying mechanism may be associated with the inhibitory effect on the CAT activity of erythrocytes. Sevoflurane also inhibited the generation of nitric oxide in erythrocytes and reduced the tolerance of erythrocytes against oxidative stress damage due to $\mathrm{H}_{2} \mathrm{O}_{2}$.
\end{abstract}

Correspondence to: Professor Guo-Rong Zhang, Department of Pain, Air Force General Hospital, PLA, 30 Fucheng Road, Beijing 100142, P.R. China

E-mail: ybjjcn@163.com

Key words: sevoflurane, erythrocyte, catalase, nitric oxide, decay

\section{Introduction}

The quantity, size and function changes of erythrocytes have been demonstrated to be independent risk factors for the development of cardiovascular diseases (1). Subsequent to general anesthesia, patients presented a reduction in erythrocyte counts in their peripheral blood, while the morphology of erythrocytes is also altered $(2,3)$. Erythrocytes are the main component of the blood. The structure of mature erythrocytes is simple, without a nucleus and other subcellular organelles (4). Notably, erythrocytes are the only carrier of oxygen in the blood circulation and supply cells with oxygen through deformation, adhesion and aggregation, while they also regulate the body blood flow and affect the immune function $(5,6)$. Common pathological changes of erythrocytes include decay and necrosis. Erythrocyte death and phagocytosis by macrophages shorten the lifespan of erythrocytes and cause thrombus, which may result in severe anemia $(7,8)$, such as uremia (9) or septicemia (10). The necrotic erythrocytes can release free hemoglobin $(\mathrm{Hb})$ in order to reduce the bioavailability of nitric oxide (NO), causing changes in the biochemical metabolism, function and morphology of erythrocytes and affecting the survival and function of erythrocytes. Hydrogen peroxide $\left(\mathrm{H}_{2} \mathrm{O}_{2}\right)$, the primary active oxygen molecule in the body, can easily penetrate the cell membrane under normal physiological conditions $(11,12)$, is involved in signal transduction and has antimicrobial and anti-inflammatory properties; however, an excess of $\mathrm{H}_{2} \mathrm{O}_{2}$ induce hydroxyl radical oxidation and erythrocyte damage due to severe hemolysis necrosis. A large number of reactive oxygen species induce free radical damage to tissues and organs, as well as vascular system dysfunction, which is harmful to tissues and organs (13).

Sevoflurane, an agent used in anesthesia, has been demonstrated to reduce the antioxidant capacity of erythrocytes and release free radicals that damage erythrocytes (14). Whether sevoflurane contributes to the $\mathrm{H}_{2} \mathrm{O}_{2}$-induced reduction of $\mathrm{Hb}$ in postoperative patients has been seldom reported. When erythrocytes are treated with $\mathrm{H}_{2} \mathrm{O}_{2}$ in vitro, the distribution of phospholipids in the lipid bilayer of cell membrane is altered (15). Thus, $\mathrm{H}_{2} \mathrm{O}_{2}$ is usually used to imitate in vivo oxidation-induced cell aging and pathological damages (15). Thus, the present study used this model to investigate the oxidative damage on erythrocytes, which was induced by a low dose of $\mathrm{H}_{2} \mathrm{O}_{2}(200 \mu \mathrm{M})$ in vitro. The aim of the present study was to observe the effects of sevoflurane on the antioxidant 
A

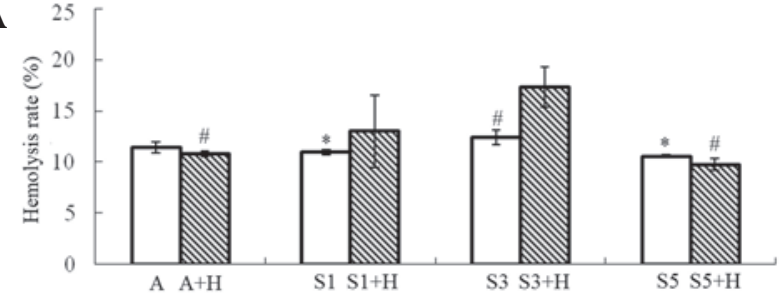

B

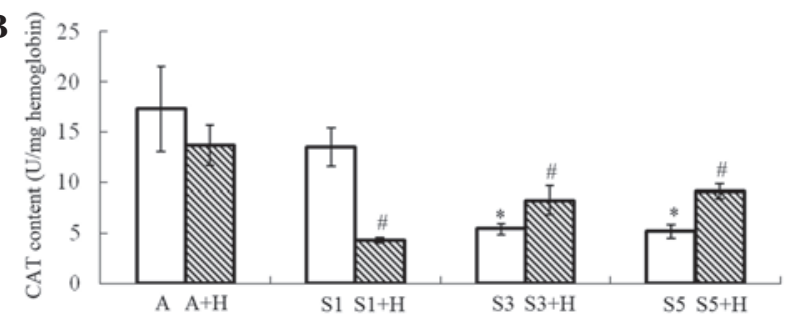

C

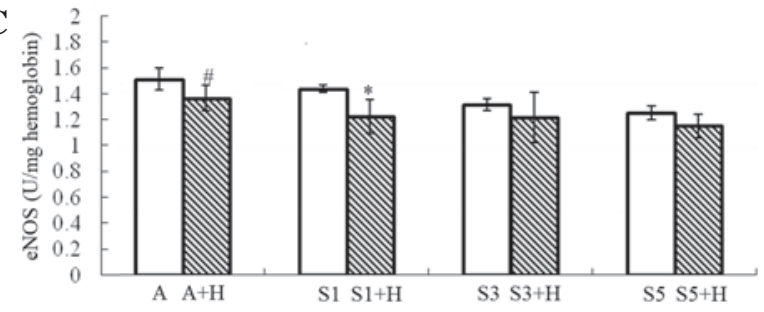

Figure 1. Hemolysis rate, CAT content and eNOS in different groups (A) Hemolysis rate. ${ }^{*} \mathrm{P}<0.05$ vs. group $\mathrm{S} 3$; ${ }^{*} \mathrm{P}<0.05$ vs. group $\mathrm{S} 3+\mathrm{H}$. (B) CAT content. ${ }^{*} \mathrm{P}<0.05$ vs. group $\mathrm{A} ;{ }^{*} \mathrm{P}<0.05$ vs. group $\mathrm{A}+\mathrm{H}$. (C) ${ }^{*} \mathrm{P}<0.05$ vs. group $\mathrm{S} 1 ;{ }^{\text {" }} \mathrm{P}<0.05$ vs. group $\mathrm{A}$. CAT, catalase; eNOS, endothelial nitric oxide synthase.

capacity, $\mathrm{NO}$ metabolism and lifespan of erythrocytes, in the presence or absence of $\mathrm{H}_{2} \mathrm{O}_{2}$.

\section{Materials and methods}

Materials. Fresh blood $(12 \mathrm{ml})$ was collected from one healthy 34-year-old male volunteer at the Air Force General Hospital (Beijing, China). Following centrifugation at $256 \mathrm{x} \mathrm{g}$ for $5 \mathrm{~min}$ at $4^{\circ} \mathrm{C}$, the plasma was removed and the erythrocytes were obtained. Ringer's solution containing $1 \%$ glucose (Fuzhou Maixin Biotechnology Development Co., Ltd., Fuzhou, China) was added to the erythrocytes, then the $2 \%$ erythrocyte suspension in Ringer's solution was obtained. Next, the erythrocyte suspension was divided into eight groups as follows: Group A, without any treatment (only ventilation of air for $30 \mathrm{~min}$; group S1, treated with $1 \%$ sevoflurane (Jiangsu Hengrui Medicine Co., Ltd, Jiangsu, China); group S3, treated with 3\% sevoflurane; group S5, treated with $5 \%$ sevoflurane; group $\mathrm{A}+\mathrm{H}$, treated with air $+\mathrm{H}_{2} \mathrm{O}_{2}$ (no. 110618; Beijing Haiderun Pharmacy Co., Ltd., Beijing, China); group $\mathrm{S} 1+\mathrm{H}$, treated with $1 \%$ sevoflurane $+\mathrm{H}_{2} \mathrm{O}_{2}$; group $\mathrm{S} 3+\mathrm{H}, 3 \%$ sevoflurane $+\mathrm{H}_{2} \mathrm{O}_{2}$; and group $\mathrm{S} 5+\mathrm{H}, 5 \%$ sevoflurane $+\mathrm{H}_{2} \mathrm{O}_{2}$. In addition, a negative control group (with distilled water replacing glucose and $\mathrm{CaCl}_{2}$ ) and positive control group (with Ringer's solution replacing glucose and $\mathrm{CaCl}_{2}$ ) were established for calculating the hemolysis rate. The final concentration of $\mathrm{H}_{2} \mathrm{O}_{2}$ in each corresponding group was $200 \mu \mathrm{mol} / 1$. Each group was incubated at $37^{\circ} \mathrm{C}$ for $15 \mathrm{~h}$, then Ringer's solution was added, followed by incubation at $37^{\circ} \mathrm{C}$ for $3 \mathrm{~h}$. Subsequent to treatment, $2 \mathrm{ml}$ erythrocyte suspension from each group was sent to the laboratory of the Beijing Huaying Biotechnology Institute (Beijing, China) in order to determine the content of catalase (CAT) and endothelial NO synthase (eNOS). The remaining erythrocyte suspension in each group was used to determine the hemolysis rate using a spectrophotometer (RT-6000; Shenzhen Leidu Electronics Co., Ltd., Shenzhen, China). The hemolysis rate was calculated using the following formula: Hemolysis rate $(\%)=($ absorbance in the experimental group - absorbance in the negative control group) / (absorbance in the positive control group - absorbance in the negative absorbance) $\mathrm{x} 100$. This study was conducted in accordance with the Declaration of Helsinki and with approval from the Ethics Committee of the Air Force General Hospital. Written informed consent was obtained from all participants.

Flow cytometric analysis. Flow cytometric analysis was performed to investigate the phosphatidylserine (PS) presentation and forward scatter (FSC) of erythrocytes. Fluorescence-activated cell sorting tubes (BD Biosciences, Franklin Lakes, NJ, USA) containing the erythrocyte suspension were placed in a flow cytometer (BD Biosciences), and each tube was marked by adding $2 \mathrm{ml}$ binding buffer (dilution, X10) (BD Biosciences). Subsequently, samples of $6 \times 10^{5}$ erythrocytes/tube were collected. Erythrocyte suspension was labeled with fluorescein isothiocyanate (BD Biosciences), and the labeled PS rate and FSC values were determined using a flow cytometer (FACS420; BD Biosciences). The results were analyzed using WinMDI version 2.9 (J. Trotter 1993-1998) software.

Statistical analysis. All data were presented as the mean \pm standard deviation and compared using the one-way analysis of variance method. Experiments in each group were performed in four parallel samples and each sample was analyzed in triplicate. All statistical analyses were performed using SPSS version 13.0 software (SPSS, Inc., Chicago, IL, USA). P<0.05 was considered to indicate a statistically significant difference.

\section{Results}

Hemolysis rate. Following treatment of the erythrocyte suspension with different concentrations of sevoflurane, the hemolysis rates in group S1, S3 and S5 $(10.949 \pm 0.265,12.417 \pm 0.716$ and $10.561 \pm 0.128 \%$, respectively) exhibited no significant differences compared with group A $(11.637 \pm 0.624 \%)$. However, the hemolysis rate in group $\mathrm{S} 3$ was significantly higher compared with that in group $\mathrm{S} 1(\mathrm{P}=0.038)$ and group $\mathrm{S} 5(\mathrm{P}=0.017)$ (Fig. 1A). By contrast, upon addition of $\mathrm{H}_{2} \mathrm{O}_{2}$, the hemolysis rate in group $\mathrm{S} 3+\mathrm{H}$ increased markedly $(17.384 \pm 1.976 \%)$, and was prominently higher compared with that in group $\mathrm{A}+\mathrm{H}$ $(10.848 \pm 0.274 \% ; \mathrm{P}=0.007)$ and group $\mathrm{S} 5+\mathrm{H}(9.777 \pm 0.576 \%$; $\mathrm{P}=0.007$, Fig. 1A). Furthermore, the hemolysis rate in group $\mathrm{S} 3+\mathrm{H}$ was significantly higher compared with that in group $\mathrm{S} 3$ (P=0.027; Fig. 1A).

CAT content. The CAT content of erythrocytes was found to be reduced with increasing sevoflurane concentration. The CAT content of erythrocytes in groups S3 and S5 $(5.431 \pm 0.531$ and $5.175 \pm 0.658 \mathrm{U} / \mathrm{mg}$ hemoglobin, 
A
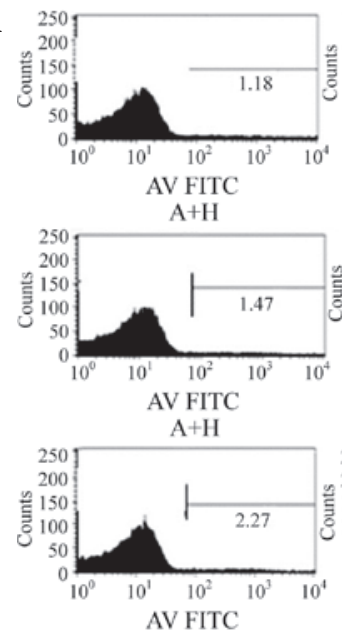

$\mathrm{A}+\mathrm{G}$

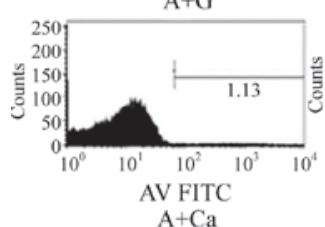

$\mathrm{A}+\mathrm{Ca}$

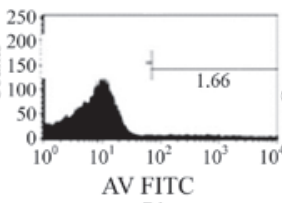

S1

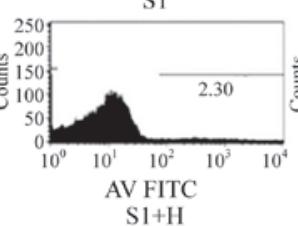

$\mathrm{S} 1+\mathrm{H}$

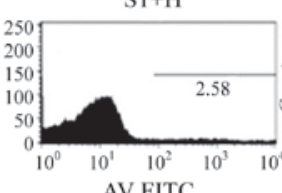

$\mathrm{S} 1+\mathrm{G}$

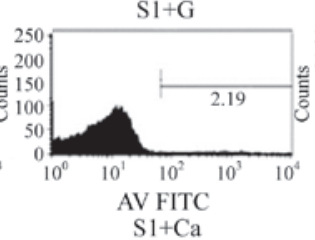

$\mathrm{S} 1+\mathrm{Ca}$

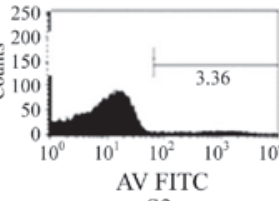

S3

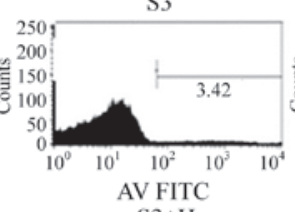

$\mathrm{S} 3+\mathrm{H}$

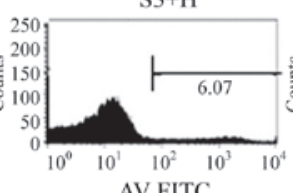

$\mathrm{S} 3+\mathrm{C}$
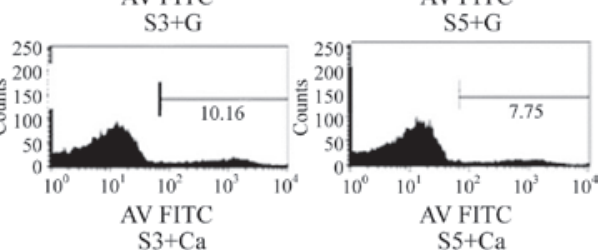

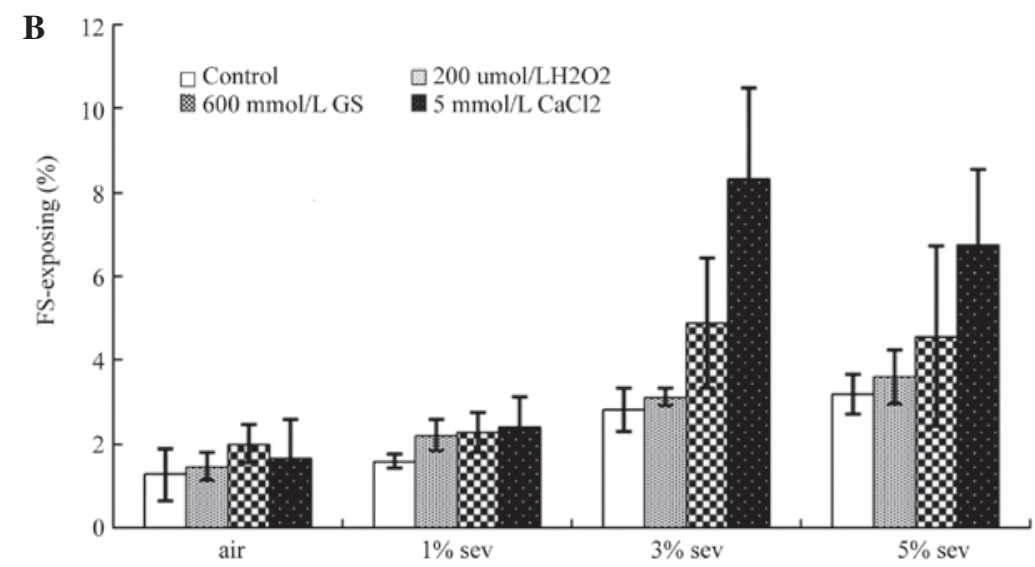

Figure 2. Effect of sevoflurane on the labeled rate of $\mathrm{H}_{2} \mathrm{O}_{2}$-induced PS ( $\left.n=4\right)$. (A) Representative histograms of each group. (B) Bar gragh for all groups. Red columns, control samples, not treated with $\mathrm{H}_{2} \mathrm{O}_{2}$; green columns, treated with $200 \mu$ mol/ $/ 1 \mathrm{H}_{2} \mathrm{O}_{2}$; yellow columns, treated with $600 \mathrm{mmol} / 1 \mathrm{GS}$; brown, treated with $5 \mathrm{mmol} / 1 \mathrm{CaCl}_{2}$; PS, phosphatidylserine; GS, glucose; sev, sevoflurane; $\mathrm{H}_{2} \mathrm{O}_{2}$, hydrogen peroxide.

respectively) decreased sharply, as compared with that in group A (17.301 $\pm 4.222 \mathrm{U} / \mathrm{mg}$ hemoglobin; $\mathrm{P}=0.009$; Fig. 1B). Similarly, the CAT content of erythrocytes in group S1 $(13.534 \pm 1.906 \mathrm{U} / \mathrm{mg}$ hemoglobin) decreased as well, but no statistically significant difference was observed compared with that in group $\mathrm{A}(\mathrm{P}=0.217)$. Upon addition of $\mathrm{H}_{2} \mathrm{O}_{2}, 1 \%$ sevoflurane was able to markedly reduce the CAT content of erythrocytes $(4.319 \pm 0.235 \mathrm{U} / \mathrm{mg}$ hemoglobin), as compared with that in group $\mathrm{A}+\mathrm{H}(13.689 \pm 2.003 \mathrm{U} / \mathrm{mg}$ hemoglobin; $\mathrm{P}=0.002$; Fig. 1B). However, the CAT content of erythrocytes increased with increasing concentration of sevoflurane (group $\mathrm{S} 3+\mathrm{H}, 8.257 \pm 1.389 \mathrm{U} / \mathrm{mg}$ hemoglobin, and group $\mathrm{S} 5+\mathrm{H}$, $9.156 \pm 0.742 \mathrm{U} / \mathrm{mg}$ hemoglobin); however, the CAT content in groups $\mathrm{S} 3+\mathrm{H}$ and $\mathrm{S} 5+\mathrm{H}$ remained significantly lower compared with that in group $\mathrm{A}+\mathrm{H}(\mathrm{P}<0.05$; Fig. 1B). Furthermore, the CAT content in group $\mathrm{S} 1+\mathrm{H}$ was markedly lower compared with that in group S1 $(\mathrm{P}<0.001)$, whereas it was notably higher in groups $\mathrm{S} 3+\mathrm{H}$ and $\mathrm{S} 5+\mathrm{H}$ compared with that in groups $\mathrm{S} 3$ and $\mathrm{S} 5$, respectively $(\mathrm{P}<0.05$; Fig. $1 \mathrm{~B})$.
eNOS content. The eNOS content of erythrocytes was not evidently affected by sevoflurane treatment alone. However, in the $\mathrm{H}_{2} \mathrm{O}_{2}$ groups, it was significantly reduced by $1 \%$ sevoflurane (group $\mathrm{S} 1+\mathrm{H} ; \mathrm{P}=0.002$ ), but not by 3 or $5 \%$ sevoflurane (groups $\mathrm{S} 3+\mathrm{H}$ and $\mathrm{S} 5+\mathrm{H}$; Fig. $1 \mathrm{C}$ ). In the air-treated groups, $\mathrm{H}_{2} \mathrm{O}_{2}$ treatment markedly increased the eNOS content of erythrocytes (P<0.001; Fig. 1C).

PS exposure. As compared with group A, treatment with $200 \mu \mathrm{mol} / 1 \mathrm{H}_{2} \mathrm{O}_{2}, 600 \mathrm{mmol} / \mathrm{l}$ glucose or $5 \mathrm{mmol} / 1 \mathrm{CaCl}_{2}$ did not prominently increase the labeled PS rate. By contrast, sevoflurane was found to increase the labeled PS rate in a concentration-dependent manner (Fig. 2A and B). In the groups treated with $\mathrm{H}_{2} \mathrm{O}_{2}$ or glucose, sevoflurane increased the labeled PS rate, which reached a peak value upon treatment with $3 \%$ sevoflurane $(\mathrm{P}<0.01)$, but then decreased. However, in the groups treated with air or $\mathrm{CaCl}_{2}$, the labeled PS rate increased gradually with increasing concentration of sevoflurane (Fig. 2A and B). 
A

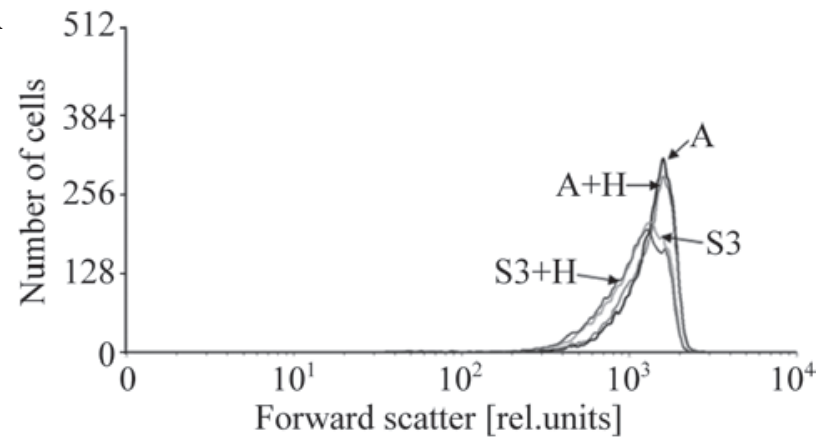

B

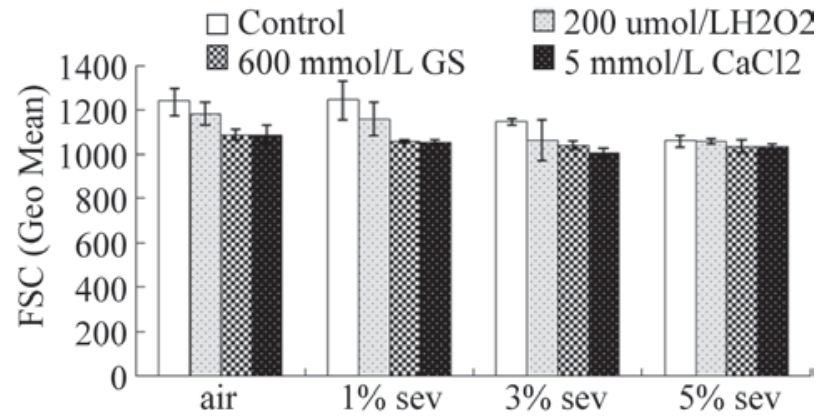

Figure 3. Effects of sevoflurane on the FSC of erythrocytes $(n=4)$ (A) Representative histogram of forward scatter. (B) Bar gragh for all groups. Red columns, control samples, not treated with $\mathrm{H}_{2} \mathrm{O}_{2}$; green columns, treated with $200 \mu \mathrm{mol} / 1 \mathrm{H}_{2} \mathrm{O}_{2}$; yellow columns, treated with $600 \mathrm{mmol} / 1 \mathrm{GS}$; brown, treated with $5 \mathrm{mmol} / \mathrm{C} \mathrm{CaCl}_{2}$; GS, glucose; sev, sevoflurane; $\mathrm{H}_{2} \mathrm{O}_{2}$, hydrogen peroxide; FSC, forward scatter.

$F S C$. In order to investigate the effects of sevoflurane on the volume of erythrocytes, the FSC of erythrocytes was also determined by flow cytometry (Fig. 3A). Upon treatment of the erythrocyte suspension with air or $200 \mu \mathrm{mol} / 1 \mathrm{H}_{2} \mathrm{O}_{2}$, sevoflurane was able to gradually reduce the FSC of erythrocytes $(\mathrm{P}<0.05)$. However, in the groups treated with $600 \mathrm{mmol} / 1$ glucose or $5 \mathrm{mmol} / 1 \mathrm{CaCl}_{2}$, sevoflurane exerted no significant effect on the volume of erythrocytes ( $\mathrm{P}>0.05$; Fig. 3B).

\section{Discussion}

The primary source of reactive oxygen species in erythrocytes is $\mathrm{Hb}$. The underlying mechanism involves polarization of the $\mathrm{Fe}-\mathrm{O}$ bond (between heme iron and oxygen), after which $\mathrm{Hb}$ is oxidized spontaneously and produces peroxide (16). CAT is a type of conjugase that uses iron porphyrin as its prosthetic group and has a strong radical scavenging function, which can protect the tissues from oxidative damage (17). With the action of CAT, $\mathrm{H}_{2} \mathrm{O}_{2}$ transforms into water and $\mathrm{O}_{2}$, preventing $\mathrm{H}_{2} \mathrm{O}_{2}$ from reacting with $\mathrm{O}_{2}^{-}$and producing $\mathrm{OH}^{-}$in the presence of iron chelating agents (16). When CAT inactivates $\mathrm{H}_{2} \mathrm{O}_{2}$, its consumption increases and thereby causes the deterioration of its activity. In endothelial cells, $200 \mu \mathrm{mol} / 1 \mathrm{H}_{2} \mathrm{O}_{2}$ can induce erythrocyte decay and death in vitro, characterized by PS exposure and cell size reduction. Its underlying mechanism mainly includes peroxidation damage on erythrocytes caused by free radicals, which is induced by $\mathrm{H}_{2} \mathrm{O}_{2}$ (18). The present study identified that with the increase of the sevoflurane concentration, the hemolysis rate of erythrocytes increased initially and then showed a downward trend. The results indicated that the CAT content of erythrocytes was significantly reduced following sevoflurane treatment when compared with the air group, and the reduction was positively correlated with the concentration of sevoflurane; these findings have also been confirmed in humans in a previous study (19). In terms of the hemolysis rate of erythrocytes, there was no statistically significant difference in the air group treated with or without $\mathrm{H}_{2} \mathrm{O}_{2}$. In the presence of $\mathrm{H}_{2} \mathrm{O}_{2}$, sevoflurane had a more significant effect on the hemolysis rate of erythrocytes, with its effect reaching a peak at the concentration of $3 \%$ and then reducing at a higher sevoflurane concentration. A previous study reported that sevoflurane can also cause liver and kidney function damage through the damage of red blood cells (20). Compared with intravenous anesthesia, sevoflurane reduces the antioxidant capacity of erythrocytes (21) and improves lipid peroxidation by inhibiting the content of CAT and other antioxidant enzymes, and thereby causing cell hemolysis and necrosis. However, the effects of sevoflurane on animal and humans are not similar (22), and thus, the results of in vitro experiments should be generalized with caution.

As a relatively stable gas free radical, NO exerts a dual biological function in humans. Under normal physiological conditions, NO can adjust the normal physiological function of the human body (23); however, NO is harmful to the body when present at extremely high or low concentrations in vivo (24). NO can induce the production of CAT, strengthening the cell's resistance against $\mathrm{H}_{2} \mathrm{O}_{2}$ (25). The classic pathway for the production of $\mathrm{NO}$ depends on the activity of NOS, which gradually oxidizes L-arginine into L-guanidine amino acid and produces NO. In addition, NO is able to dilate blood vessels, relax the vascular smooth muscle and inhibit the proliferation of endothelial cells (26). Previous studies on sevoflurane revealed its direct role in the inhibition of endothelial cells, releasing NO (27). In the present study, the eNOS content in group $\mathrm{S} 1+\mathrm{H}$ was lower compared with that in group $\mathrm{A}+\mathrm{H}$, indicating that in the presence of $\mathrm{H}_{2} \mathrm{O}_{2}$, sevoflurane is able to inhibit the activity of eNOS and thereby reduce the NO content in red blood cells.

As detected by flow cytometry, the labeled rate of PS represents the decay and death rate of erythrocytes (28), while changes in the FSC value represent changes in the volume of erythrocytes, with a decreased FSC value indicating a reduced cell size (29). In the present study, the labeled rate of PS was found to increase with increasing concentration of sevoflurane, while the FSC was found to be reduced. Furthermore, in the presence of $\mathrm{H}_{2} \mathrm{O}_{2}$, the effect of sevoflurane in reducing the erythrocyte antioxidative capacity was improved. As a result, a high concentration of inhaled sevoflurane is able to induce red blood cell decay and death, and reduce the antioxidant capacity of erythrocytes.

$\mathrm{H}_{2} \mathrm{O}_{2}$, a metabolite of cells in an aerobic environment, is a type of primary active oxygen molecule with crucial biological functions, including its function as a signaling molecule and the regulation of cell division, differentiation, migration, aging or death (30). The oxidative stress or pathological conditions inducing more $\mathrm{H}_{2} \mathrm{O}_{2}$, as well as the defected or decreased anti-oxidation system of red blood cells, may cause $\mathrm{H}_{2} \mathrm{O}_{2}$ to easily react with divalent metal ions (such as $\mathrm{Fe}^{2+}$ and $\mathrm{Cu}^{2+}$ ) and form hydroxyl free radicals (also known as the Fenton reaction) with stronger oxidation capabilities, leading to 
oxidative damage on cells (12). The degree of $\mathrm{H}_{2} \mathrm{O}_{2}$-induced oxidative damage on cells mainly depends on the strength of the oxidative stress factors. The present study identified that a low dose of $\mathrm{H}_{2} \mathrm{O}_{2}$ can stimulate red blood cells exposing PS and result in cell size reduction, inducing red blood cell decay and death in vitro.

Excessive amounts of free radicals induce oxidative stress reaction in red blood cells, causing membrane lipid peroxidation damage and protein denaturation and degradation (31). Oxidative stress itself is able to selectively oxidize aminophospholipids, in particular PS, and cause their translocation and exposure, as well as cause aminophospholipid translocase deactivation. In addition, oxidative stress can activate the Fas-caspase signaling pathway and lead to PS exposure (32). Exposed PS then activates the blood clotting system, leading to local thrombosis or ischemia. Thus, high concentration of sevoflurane inhaled can induce PS exposure and cell size reduction, causing red blood cell decay and death, and can reduce the antioxidant capacity of erythrocytes.

In conclusion, sevoflurane is able to reduce the antioxidative activity of erythrocytes, decreasing their ability to resist $\mathrm{H}_{2} \mathrm{O}_{2}$ damage and increase their hemolysis rate. The underlying mechanism may be associated with the inhibitory effect of sevoflurane on the CAT activity in erythrocytes. Furthermore, sevoflurane is able to inhibit the generation of $\mathrm{NO}$ in erythrocytes, and reduce the tolerance of erythrocytes against oxidative stress damage induced by $\mathrm{H}_{2} \mathrm{O}_{2}$. The mechanism may be associated with its inhibition of eNOS activity in erythrocytes. However, the present study was conducted using an in vitro model. The function of sevoflurane requires further study in vivo and in clinical settings in order to evaluate potential hazards associated with its use.

\section{Acknowledgements}

This study was supported by Youth Project of the Chinese People's Liberation Army (No. 14QNP065).

\section{References}

1. Tsuchiya M, Asada A, Kasahara E, Sato EF, Shindo M and Inoue M: Antioxidant protection of propofol and its recycling in erythrocyte membranes. Am J Respir Crit Care Med 165: 54-60, 2002.

2. Yang XM, Liu J, Ji J and Xie J: Effects of dexmedetomidine on the deformability of erythrocytes in vitro and in anesthesia. Exp Ther Med 7: 1631-1634, 2014.

3. Yerer MB, Aydoğan S and Comu FM: Gender-related alerations in erythrocyte mechanical activities under desflurane or sevoflurane anesthesia. Clin Hemorheol Microcirc 39: 423-427, 2008

4. Berg CP, Engels IH, Rothbart A, Lauber K, Renz A, Schlosser SF, Schulze-Osthoff K and Wesselborg S: Human mature red blood cells express caspase- 3 and caspase- 8 , but are devoid of mitochondrial regulators of apoptosis. Cell Death Differ 8: 1197-1206, 2001.

5. Young IS and Woodside JV: Antioxidants in health and disease. J Clin Pathol 54: 176-186, 2001.

6. Gutteridge JM: Lipid peroxidation and anti-oxidants as biomarkers of tissue damage. Clin Chem 41: 1819-1828, 1995.

7. Lang KS, Lang PA, Bauer C, Duranton C, Wieder T, Huber SM and Lang F: Mechanisms of suicidal erythrocyte death. Cell Physiol Biochem 15: 195-202, 2005.

8. Boas FE, Forman L and Beutler E: Phosphatidylserine exposure and red cell viability in red cell aging and in hemolytic anemia. Proc Natl Acad Sci USA 95: 3077-3081, 1998.

9. Lang F, Gulbins E, Lerche H, Huber SM, Kempe DS and Foller M: Eryptosis, a window to systemic disease. Cell Physiol Biochem 22: 373-380, 2008.
10. Kempe DS, Akel A, Lang PA, Hermle T, Biswas R, Muresanu J, Friedrich B, Dreischer P, Wolz C, Schumacher U, et al: Suicidal erythrocyte death in sepsis. J Mol Med (Berl) 85: 273-281, 2007.

11. Halliwell B, Clement MV and Long LH: Hydrogen peroxide in the human body. FEBS Lett 486: 10-13, 2000.

12. Veal E and Day A: Hydrogen peroxide as a signaling molecule. Antioxid Redox Signal 15: S147-S151, 2011.

13. Vermeulen Windsant IC, Hanssen SJ, Buurman WA and Jacobs MJ: Cardiovascular surgery and organ damage: Time to reconsider the role of hemolysis. J Thorac Cardiova Surgy 142: 1-11, 2011.

14. Türkan H, Aydin A, Sayal A and Karahalil B: The effect of sevoflurane and desflurane on markers of oxidative status in erythrocyte. Toxicol Ind Health 27: 181-186, 2011.

15. Johnson RM, Goyette GJ, Ravindranath Y and Ho YS: Hemoglobin autoxidation and regulation of endogenous $\mathrm{H}_{2} \mathrm{O}_{2}$ levels in erythrocytes. Free Radic Biol Med 39: 1407-1417, 2005.

16. Yoshida KI and Okabe EO: Selective impairment of endothelium-dependent relaxation by sevoflurane: Oxygen free radicals participation. Anesthesioloy 76: 440-447, 1992.

17. Njuma OJ, Ndontsa EN and Goodwin DC: Catalase in peroxidase clothing: Interdependent cooperation of two cofactors in the catalytic versatility of KatG. Arch Biochem Biophys 544: 27-39, 2014.

18. Benfeitas R, Selvaggio G, Antunes F, Coelho PM and Sakvador A: Hydrogen peroxide metabolism and sensing in human erythrocytes: A validated kinetic model and reappraisal of the role of peroxiredoxin II. Free Radic Biol Med 74: 35-49, 2014.

19. Budić I, Pavlović D, Cvetković T, Djordjević N, Simić D, Milojević I and Stojanović M: The effects of different anesthesia techniques on free radical production after tourniquet-induced ischemia-reperfusion injury at children's age. Vojnosanit Pregl 67: 659-664, 2010.

20. Masin-Spasovska J, Dimitrovski K, Stavridis S, Stankov O, Dohcev S, Saidi S, Jakovski K, Balkanov T, Labacevski N, Stankov V, et al: Acute fulminant hepatatis in kidney transplant recipient after repeated sevoflurane anesthesia-a case report and literature review. Curr Drug Saf 8: 141-144, 2013.

21. Budic I, Pavlovic D, Kocic G, Cvetkovic T, Simic D, Basic J and Zivanovic D: Biomarkers of oxidative stress and endothelial dysfunction after tourniquet release in children. Physiol Res 60 (Suppl 1): S137-S145, 2011.

22. Soares JH, Brosnan RJ, Fukushima FB, Hodges J and Liu H: Solubility of haloether anesthetics in human and animal blood. Anesthesiology 117: 48-55, 2012.

23. Guo W, Cheng ZY and Zhu YZ: Hydrogen sulfide and translational medicine. Acta Pharmacol Sin 34: 1284-1291, 2013.

24. Lo Faro ML, Fox B, Whatmore JL, Winyard PG and Whiteman M: Hydrogen sulfide and nitric oxide interactions in inflammation. Nitric Oxide 41: 38-47, 2014.

25. Yoshioka Y,Kitao T, Kishino T, Yamamuro A and Maeda S: Nitric oxide protects macrophages from hydrogen peroxide-induced apoptosis by inducing the formation of catalase. J Immunol 176: 4675-4681, 2006.

26. Cortese-Krott MM and Kelm M: Endothelial nitric oxide synthase in red blood cells: Key to a new erythrocrine function? Redox Biol 2: 251-258, 2014.

27. Kanna T, Akata T, Izumi K, Nakashima M, Yonemitsu Y, Hashizume $M$ and Takahashi S: Sevoflurane and bradykinin-induced calcium mobilization in pulmonary arterial valvular endothelial cells in situ: Sevoflurane stimulates plasmalemmal calcium influx into endothelial cells. J Cardiovasc Pharmacol 40: 714-724, 2002.

28. Lupescu A, Bissinger R, Jilani $\mathrm{K}$ and Lang F: In vitro induction of erythrocyte phosphatidylserine translocation by the natural naphthoquinone shikonin. Toxins (Basel) 6: 1559-1574, 2014.

29. Hirsch J, Menzebach A, Welters ID, Dietrich GV, Katz N and Hempelmann G: Indicators of erythrocyte damage after microwave warming of packed red blood cells. Clin Chem 49: 792-799, 2003.

30. Weigert A and Brüne B: Nitric oxide, apoptosis and macrophagepolarization during tumor progression. Nitric Oxide 19: 95-102, 2008.

31. Perrone S, Tataranno ML, Stazzoni G, Del Vecchio A and Buonocore G: Oxidative injury in neonatal erythrocytes. J Matern Fetal Neonatal Med 25 (Suppl 5): S104-S108, 2012.

32. Tyurina YY, Tyurin VA, Zhao Q, Djukic M, Quinn PJ, Pitt BR and Kagan VE: Oxidation of phosphatidyl-serine: A mechanism for plasma membrane phospholipid scrambling during apoptosis? Biochem Biophys Res Commun 324: 1059-1064, 2004. 